\title{
Effect of Anti-Hypertensive Drugs in Geriatric Trauma Patients: A Single-Centre, Retrospective Cohort Study
}

Hiroki Nagasawa ( $\square$ hi-nagasawa@juntendo.ac.jp )

Juntendo Shizuoka Hospital: Juntendo Daigaku Igakubu Fuzoku Shizuoka Byoin https://orcid.org/0000-0001-7825-4244

Kouhei Ishikawa Juntendo Shizuoka Hospital: Juntendo Daigaku Igakubu Fuzoku Shizuoka Byoin

Souichirou Ota Juntendo Shizuoka Hospital: Juntendo Daigaku Igakubu Fuzoku Shizuoka Byoin

\section{Ken-ichi Muramatsu}

Juntendo Shizuoka Hospital: Juntendo Daigaku Igakubu Fuzoku Shizuoka Byoin

Yoshihiro Kushida

Juntendo Shizuoka Hospital: Juntendo Daigaku Igakubu Fuzoku Shizuoka Byoin

Kei Jitsuiki

Juntendo Shizuoka Hospital: Juntendo Daigaku Igakubu Fuzoku Shizuoka Byoin

Hiromichi Ohsaka

Juntendo Shizuoka Hospital: Juntendo Daigaku Igakubu Fuzoku Shizuoka Byoin

Youichi Yanagawa

Juntendo Shizuoka Hospital: Juntendo Daigaku Igakubu Fuzoku Shizuoka Byoin

\section{Research article}

Keywords: Oral anti-hypertensive drug, Outcome, Propensity score-matched analysis, Trauma.

Posted Date: September 29th, 2021

DOl: https://doi.org/10.21203/rs.3.rs-923979/v1

License: (c) (i) This work is licensed under a Creative Commons Attribution 4.0 International License. Read Full License 


\section{Abstract}

Background: The relationship between the administration of oral anti-hypertensive drugs and mortality after hospitalisation in trauma patients has not yet been investigated. We conducted a single-centre, retrospective cohort study to determine the effect of anti-hypertensive drugs on mortality and complications in geriatric trauma patients.

Methods: Trauma patients aged $\geq 65$ years who were admitted to our hospital between January 2018 and December 2020 were analysed. Patients who had not received anti-hypertensive drugs before admission [AHT(-) group] and those who had received anti-hypertensive drugs before admission [AHT(+) group] were compared using 1:1 propensity score-matched analysis. The primary outcome was 28-day mortality, and the secondary outcomes were in-hospital mortality and the incidence of complications during hospitalisation. Outcomes were analysed by calculating the relative risk.

Results: A total of 637 patients were included in our study. After propensity score matching, each study group had 223 patients. There was no significant difference in the primary outcome between the two groups [28-day mortality: $\mathrm{AHT}(-)$ group vs. $\mathrm{AHT}(+)$ group: $3.6 \%$ vs. 3.6\%, respectively; adjusted relative risk: $1.00 ; 95 \%$ confidence interval: $0.38-2.62$ ]. Regarding secondary outcomes, only the incidence of inhospital delirium was significantly different between the AHT(-) group and the AHT(+) group $(25.1 \%$ vs. $13.9 \%$, respectively; adjusted relative risk: $0.55 ; 95 \%$ confidence interval: $0.37-0.82$ ).

Conclusions: Regular use of anti-hypertensive drugs did not affect the outcome of geriatric trauma patients. However, the incidence of in-hospital delirium was reduced in patients regularly receiving antihypertensive drugs.

\section{Background}

The world population is aging and will continue growing older, including in Japan. Older adults have higher trauma mortality rates due to various factors, such as multidrug administration, a medical history, muscle weakness, poor nutrition, and weakened immunity [1-5]. In addition, they often die from complications (e.g., infections and embolism), even if the trauma itself is mild [5-8].

On the one hand, the regular administration of anti-hypertensive drugs is a risk factor for falls in older adults [9-12]. On the other hand, anti-hypertensive drugs are expected to exhibit anti-inflammatory effects [13]. Particularly in patients with sepsis, a better prognosis has been reported in those regularly taking anti-hypertensive drugs [14-17]. To our knowledge, the relationship between the administration of oral anti-hypertensive drugs and mortality after hospitalisation in trauma patients has not yet been investigated.

Herein, we present the potential effects of anti-hypertensive drugs in trauma patients. This study contributes to a growing body of evidence for improved care after admission for this vulnerable 
population. It is expected that this study will further research on medication management following admission.

We hypothesised that trauma patients receiving anti-hypertensive drugs would have a better prognosis than those who did not receive anti-hypertensive drugs. This was assessed by evaluating 28-day mortality, the primary outcome of this study.

\section{Methods}

\section{Study design and setting}

All procedures performed in studies involving human participants were in accordance with the ethical standards of the institutional and/or national research committee and with the 1964 Declaration of Helsinki and its later amendments or comparable ethical standards. The protocol for this single-centre, retrospective cohort study was approved by the Medical Ethics Committee of Juntendo University Shizuoka Hospital (approval number: E21-0089). This institution delivers critical trauma care to an area with a population of $1,500,000$. The study was conducted in accordance with the Strengthening the Reporting of Observational Studies in Epidemiology guidelines [18].

\section{Selection of participants}

We collected the data of older trauma patients ( $\geq 65$ years) who were admitted to our hospital between January 2018 and December 2020. Patients admitted for cardiac arrest, burns, toxins, asphyxiation, neardrowning, or hanging were excluded. Moreover, patients who were transferred to another hospital within 3 days of admission, and those with unclear medical and drug histories, were excluded.

\section{Measurements}

This observational study used a medical chart review to collect data. In this study, collectors who were not authors collected the necessary information from the medical records. Next, supervisors checked and anonymised the collected data. After these processes, the authors analysed the data. The following data were collected: patient demographics, medical history, injury severity score (ISS), vital signs upon arrival (Glasgow coma scale score, systolic blood pressure, heart rate, respiratory rate, and body temperature), inhospital complications (acute kidney injury, acute respiratory distress syndrome, arrhythmia, bleeding, cardiovascular disease, delirium, infections, stroke, and venous thromboembolism [VTE]), 'do not attempt resuscitation' orders, invasive treatments received within 24 hours of admission (blood transfusion, emergency operation under general anaesthesia, interventional radiology, and tracheal intubation), and 28-day or in-hospital mortality.

\section{Definition}

In this study, we defined 'anti-hypertensive medication' as a history of prescribing anti-hypertensive drugs and taking these medications within 28 days before the injury. 


\section{Outcomes}

The primary outcome was 28-day mortality, which was selected with reference to the results of previous studies [14-17]. The secondary outcomes were in-hospital mortality and the incidence of in-hospital complications (acute kidney injury, acute respiratory distress syndrome, arrhythmia, bleeding, cardiovascular disease, delirium, infections, stroke, and VTE). These variables were selected based on their impact on the prognosis of trauma patients after admission.

\section{Statistical analyses}

Patients who had not received anti-hypertensive drugs before hospital admission [AHT(-) group] and those who had received anti-hypertensive drugs before hospital admission [AHT(+) group] were compared using 1:1 propensity score-matched analysis. Logistic regression analysis was used to estimate propensity scores. The variables included in the model were age, sex, type of injury, vital signs on arrival, ISS, 'do not attempt resuscitation' orders, treatments received within 24 hours of admission, and comorbidities. We used a calliper width of 0.2 of the standard deviation of the logit of the propensity score. The balance between both groups was evaluated using the standardised mean difference (SMD), with an SMD >0.1 as a significant imbalance. Data are presented as the median (interquartile range), or as the number (percentage), as appropriate. Thereafter, outcomes were compared in the matched cohort. The relative risk (RR) was calculated, and the difference-along with the $95 \%$ confidence interval $(\mathrm{Cl})$-are reported herein.

Missing values were handled using pairwise methods. All statistical analyses were performed using EZR 1.54 (Saitama Medical Center, Jichi Medical University, Saitama, Japan), a graphical user interface for R 4.0.2 (The R Foundation for Statistical Computing, Vienna, Austria) [19]. For sensitivity analysis, matching was also performed on patients with an ISS $\geq 16$, and the same outcomes were evaluated.

All results were considered statistically significant based on a $P$-value $<0.05$, or the width of the $95 \% \mathrm{Cl}$.

\section{Results}

\section{Characteristics of the study subjects}

A total of 5,641 trauma patients were treated in our emergency room, of whom 1,043 satisfied the inclusion criteria. After excluding 406 patients, 637 patients were analysed in our study. Based on the medication history, we divided this population into two groups: the AHT(-) and AHT (+) groups. Using the propensity score estimated by a multivariable logistic regression analysis of 637 patients, we obtained 223 patients in each group (Fig. 1). The c-statistic for the goodness-of-fit model was 0.70 (95\% Cl: 0.660.74). Table 1 shows the baseline characteristics of the patients before propensity score matching. In the matched population, there were no significant differences in the baseline characteristics of the patients between the two groups (Table 2). 
Page 5/19 
Table 1

Baseline characteristics of older trauma patients who had and had not received anti-hypertensive drugs

\begin{tabular}{|c|c|c|c|c|}
\hline Characteristics & $\begin{array}{l}\text { AHT(-) group } \\
(n=331)\end{array}$ & $\begin{array}{l}\text { AHT(+) group } \\
(n=306)\end{array}$ & $P$-value & SMD \\
\hline Age, years & $75[70,82]$ & $78[72,84]$ & $<0.001$ & 0.273 \\
\hline Sex, n (\%) & & & 0.570 & 0.050 \\
\hline Male & $205(61.9)$ & $182(59.5)$ & & \\
\hline Female & $126(38.1)$ & $124(41.5)$ & & \\
\hline Type of injury, n (\%) & & & 0.302 & 0.092 \\
\hline Blunt & $321(97.0)$ & $301(98.4)$ & & \\
\hline Penetrative & $10(3.0)$ & $5(1.6)$ & & \\
\hline Injury severity score & $10[5,17]$ & $9[5,16]$ & 0.156 & 0.091 \\
\hline \multicolumn{5}{|l|}{ Vital signs upon arrival } \\
\hline Systolic blood pressure, $\mathrm{mmHg}$ & $144[120,162]$ & $148[128,164]$ & 0.143 & 0.116 \\
\hline Heart rate, bpm & $80[69,93]$ & $81[70,93]$ & 0.633 & 0.007 \\
\hline Respiratory rate, bpm & $20[17,23]$ & $20[16,21]$ & 0.125 & 0.160 \\
\hline Glasgow coma scale & $15[14,15]$ & $15[14,15]$ & 0.137 & 0.039 \\
\hline Body temperature, ${ }^{\circ} \mathrm{C}$ & $36.5[36.2,36.8]$ & $36.5[36.1,36.8]$ & 0.223 & 0.003 \\
\hline \multicolumn{5}{|l|}{ Comorbidities, n (\%) } \\
\hline Autoimmune disease & $8(2.4)$ & $8(2.6)$ & 1.000 & 0.013 \\
\hline Chronic heart failure & $7(2.1)$ & $13(4.2)$ & 0.172 & 0.122 \\
\hline Chronic kidney disease & $10(3.0)$ & $30(9.8)$ & $<0.001$ & 0.280 \\
\hline Chronic liver disease & $8(2.4)$ & $11(3.6)$ & 0.486 & 0.069 \\
\hline Chronic lung disease & $14(4.2)$ & $18(5.9)$ & 0.368 & 0.075 \\
\hline Dementia & $22(6.6)$ & $22(7.2)$ & 0.876 & 0.021 \\
\hline Diabetes mellitus & $50(15.1)$ & $80(26.1)$ & 0.001 & 0.275 \\
\hline
\end{tabular}

All categorical variables are presented as numbers and percentages (\%), whereas all numerical variables are presented as medians (interquartile range). The balance between the two groups was evaluated using the SMD, with an SMD $>0.1$ as a significant imbalance.

Abbreviations: AHT, anti-hypertensive drug; DNAR, do not attempt resuscitation; SMD, standardised mean difference. 


\begin{tabular}{|c|c|c|c|c|}
\hline Characteristics & $\begin{array}{l}\text { AHT(-) group } \\
(n=331)\end{array}$ & $\begin{array}{l}\text { AHT(+) group } \\
(n=306)\end{array}$ & $P$-value & SMD \\
\hline Malignancy & $17(5.1)$ & $16(5.2)$ & 1.000 & 0.004 \\
\hline Old myocardial infarction & $8(2.4)$ & $28(9.2)$ & $<0.001$ & 0.291 \\
\hline Psychiatric disease & $10(3.0)$ & $10(3.3)$ & 1.000 & 0.014 \\
\hline Stroke & $20(6.0)$ & $52(17.0)$ & $<0.001$ & 0.348 \\
\hline DNAR order, n (\%) & $2(0.6)$ & $4(1.3)$ & 0.435 & 0.072 \\
\hline \multicolumn{5}{|c|}{ Treatment received within 24 hours of admission, $n(\%)$} \\
\hline Blood transfusion & $69(20.8)$ & $60(19.6)$ & 0.767 & 0.031 \\
\hline Emergency operation & $49(14.8)$ & $50(16.3)$ & 0.662 & 0.042 \\
\hline Interventional radiology & $14(4.2)$ & $15(4.9)$ & 0.708 & 0.032 \\
\hline Tracheal intubation & $42(12.7)$ & $34(11.1)$ & 0.625 & 0.049 \\
\hline \multicolumn{5}{|c|}{$\begin{array}{l}\text { All categorical variables are presented as numbers and percentages (\%), whereas all numerical } \\
\text { variables are presented as medians (interquartile range). The balance between the two groups was } \\
\text { evaluated using the SMD, with an SMD }>0.1 \text { as a significant imbalance. }\end{array}$} \\
\hline \multicolumn{5}{|c|}{$\begin{array}{l}\text { Abbreviations: AHT, anti-hypertensive drug; DNAR, do not attempt resuscitation; SMD, standardised } \\
\text { mean difference. }\end{array}$} \\
\hline
\end{tabular}


Table 2

Characteristics of the study population after propensity score matching

\begin{tabular}{|c|c|c|c|c|}
\hline Characteristics & $\begin{array}{l}\text { AHT(-) group } \\
(n=223)\end{array}$ & $\begin{array}{l}\text { AHT(+) group } \\
(n=223)\end{array}$ & $P$-value & SMD \\
\hline Age, years & $77[71,83]$ & $77[72,84]$ & 0.723 & 0.037 \\
\hline Sex, n (\%) & & & 1.000 & 0.009 \\
\hline Male & $130(58.3)$ & $129(57.8)$ & & \\
\hline Female & $93(41.7)$ & $94(42.2)$ & & \\
\hline Type of injury, n (\%) & & & 1.000 & 0.036 \\
\hline Blunt & $220(98.7)$ & $219(98.2)$ & & \\
\hline Penetrative & $3(1.3)$ & $4(1.8)$ & & \\
\hline Injury severity score & $9[5,17]$ & $9[4,14]$ & 0.426 & 0.057 \\
\hline \multicolumn{5}{|l|}{ Vital signs upon arrival } \\
\hline Systolic blood pressure, $\mathrm{mmHg}$ & $147[124,165]$ & $148[128,164]$ & 0.956 & 0.028 \\
\hline Heart rate, bpm & $80[68,90]$ & $81[69,91]$ & 0.429 & 0.058 \\
\hline Respiratory rate, bpm & $20[16,22]$ & $20[16,22]$ & 0.785 & 0.052 \\
\hline Glasgow coma scale & $15[14,15]$ & $15[14,15]$ & 0.109 & 0.020 \\
\hline Body temperature, ${ }^{\circ} \mathrm{C}$ & $36.5[36.3,36.8]$ & $36.5[36.1,36.8]$ & 0.268 & 0.090 \\
\hline \multicolumn{5}{|l|}{ Comorbidities, n (\%) } \\
\hline Autoimmune disease & $5(2.2)$ & $4(1.8)$ & 1.000 & 0.032 \\
\hline Chronic heart failure & $6(2.7)$ & $7(3.1)$ & 1.000 & 0.027 \\
\hline Chronic kidney disease & $10(4.5)$ & $13(5.8)$ & 0.669 & 0.061 \\
\hline Chronic liver disease & $7(3.1)$ & $7(3.1)$ & 1.000 & $<0.001$ \\
\hline Chronic lung disease & $11(4.9)$ & $11(4.9)$ & 1.000 & $<0.001$ \\
\hline Dementia & $16(7.2)$ & $18(8.1)$ & 0.859 & 0.034 \\
\hline Diabetes mellitus & $45(20.2)$ & $41(18.4)$ & 0.719 & 0.045 \\
\hline
\end{tabular}

All categorical variables are presented as numbers and percentages (\%), whereas all numerical variables are presented as medians (interquartile range). The balance between the two groups was evaluated using the SMD, with an SMD $>0.1$ as a significant imbalance.

Abbreviations: AHT, anti-hypertensive drug; DNAR, do not attempt resuscitation; SMD, standardised mean difference. 


\begin{tabular}{|c|c|c|c|c|}
\hline Characteristics & $\begin{array}{l}\text { AHT(-) group } \\
(n=223)\end{array}$ & $\begin{array}{l}\text { AHT(+) group } \\
(n=223)\end{array}$ & $P$-value & SMD \\
\hline Malignancy & $13(5.8)$ & $13(5.8)$ & 1.000 & $<0.001$ \\
\hline Old myocardial infarction & $8(3.6)$ & $8(3.6)$ & 1.000 & $<0.001$ \\
\hline Psychiatric disease & $7(3.1)$ & $8(3.6)$ & 1.000 & 0.025 \\
\hline Stroke & $20(9.0)$ & $21(9.4)$ & 1.000 & 0.016 \\
\hline DNAR order, n (\%) & $2(0.9)$ & $3(1.3)$ & 1.000 & 0.043 \\
\hline \multicolumn{5}{|c|}{ Treatment received within 24 hours of admission, $\mathrm{n}(\%)$} \\
\hline Blood transfusion & $69(20.8)$ & $60(19.6)$ & 0.767 & 0.031 \\
\hline Emergency operation & $49(14.8)$ & $50(16.3)$ & 0.662 & 0.042 \\
\hline Interventional radiology & $14(4.2)$ & $15(4.9)$ & 0.708 & 0.032 \\
\hline Tracheal intubation & $42(12.7)$ & $34(11.1)$ & 0.625 & 0.049 \\
\hline \multicolumn{5}{|c|}{$\begin{array}{l}\text { All categorical variables are presented as numbers and percentages (\%), whereas all numerical } \\
\text { variables are presented as medians (interquartile range). The balance between the two groups was } \\
\text { evaluated using the SMD, with an SMD }>0.1 \text { as a significant imbalance. }\end{array}$} \\
\hline
\end{tabular}

\section{Main results}

Table 3 shows the outcomes of the matched cohort. There was no significant difference in terms of the primary outcome (i.e., 28-day mortality) between the two groups [AHT(-) group vs. AHT(+) group: 3.6\% vs. 3.6\%, respectively; adjusted RR: $1.00 ; 95 \% \mathrm{Cl}$ : 0.38-2.62]. Regarding secondary outcomes, only the incidence of in-hospital delirium was significantly different between the two groups, with that in the $\mathrm{AHT}(+)$ group being significantly lower than that in the AHT(-) group $[13.9 \%$ vs. $25.1 \%$, respectively; adjusted RR: $0.55 ; 95 \% \mathrm{Cl}: 0.37-0.82$ ]. Table 4 summarises the total causes of death during hospitalisation in the matched cohort. There was no significant difference in the causes of death between the two groups. 
Table 3

Primary and secondary outcomes

\begin{tabular}{|c|c|c|c|}
\hline Variables & $\begin{array}{l}\text { AHT(-) group, } \\
(n=223)\end{array}$ & $\begin{array}{l}\text { AHT(+) group, } \\
(n=223)\end{array}$ & $\begin{array}{l}\text { Relative risk } \\
\text { [95\% Cl] }\end{array}$ \\
\hline 28-day mortality, n (\%) & $8(3.6)$ & $8(3.6)$ & $1.000[0.382-2.618]$ \\
\hline In-hospital mortality, n (\%) & $11(4.9)$ & $11(4.9)$ & $1.000[0.443-2.259]$ \\
\hline \multicolumn{4}{|l|}{ Complications, n (\%) } \\
\hline Acute kidney injury & $8(3.6)$ & $7(3.1)$ & $0.875[0.323-2.372]$ \\
\hline ARDS & $8(3.6)$ & $6(2.7)$ & $0.750[0.265-2.126]$ \\
\hline Arrhythmia & $19(8.5)$ & $17(7.6)$ & $0.895[0.478-1.676]$ \\
\hline Bleeding & $7(3.1)$ & $4(1.8)$ & $0.571[0.170-1.925]$ \\
\hline Cardiovascular disease & $6(2.7)$ & $6(2.7)$ & $1.000[0.328-3.053]$ \\
\hline Delirium & $56(25.1)$ & $31(13.9)$ & $0.554[0.372-0.824]$ \\
\hline Infections & $48(21.5)$ & $46(20.6)$ & 0.958 [0.669-1.373] \\
\hline Stroke & $7(3.1)$ & $4(1.8)$ & $0.571[0.170-1.925]$ \\
\hline VTE & $11(4.9)$ & $4(1.8)$ & $0.364[0.118-1.125]$ \\
\hline \multicolumn{4}{|c|}{ All results were considered statistically significant based on the width of the $95 \% \mathrm{Cl}$. } \\
\hline
\end{tabular}


Table 4

Causes of death in the matched cohort

\begin{tabular}{|c|c|c|c|}
\hline Causes of death & AHT(-) group $(n=11)$ & AHT $(+)$ group $(n=11)$ & $P$-value \\
\hline Bleeding, n (\%) & $0(0.0)$ & $1(9.1)$ & 1.000 \\
\hline Brain death, n (\%) & $6(54.5)$ & $3(27.3)$ & 0.387 \\
\hline Heart failure, n (\%) & $1(9.1)$ & $1(9.1)$ & 1.000 \\
\hline Infection, n (\%) & $3(27.3)$ & $2(18.2)$ & 1.000 \\
\hline Others ${ }^{\mathrm{a}}, \mathrm{n}(\%)$ & $1(9.1)$ & $4(36.4)$ & 0.311 \\
\hline \multicolumn{4}{|c|}{$\begin{array}{l}\text { Data were compared using Fisher's exact test. Results were considered statistically significant based } \\
\text { on a } P \text {-value }<0.05 \text {. }\end{array}$} \\
\hline \multicolumn{4}{|c|}{ a Others include aortic dissection, terminal cancer, multiple organ failure, and natural death. } \\
\hline Abbreviation: AHT, & Dertensive drug. & & \\
\hline
\end{tabular}

In the sensitivity analysis, 187 patients with an ISS $\geq 16$ were extracted from the study population, and 55 patients were matched in both groups (Table 5). In the matched cohort, some variables (age, sex, comorbidities [dementia and diabetes mellitus]) were not balanced. In this analysis, the incidence of delirium was also lower in the AHT(+) group than in the AHT(-) group (19.1\% vs. 46.9\%, respectively; adjusted RR: 0.39; 95\% Cl: 0.20-0.77) (Table 6). 
Table 5

Characteristics of patients with an ISS $\geq 16$ after propensity score matching

\begin{tabular}{|c|c|c|c|c|}
\hline Characteristics & $\begin{array}{l}\text { AHT(-) group } \\
(n=55)\end{array}$ & $\begin{array}{l}\text { AHT (+) group } \\
(n=55)\end{array}$ & $P$-value & SMD \\
\hline Age, years & $76[70,84]$ & $75[71,81]$ & 0.584 & 0.144 \\
\hline Sex, n (\%) & & & 0.687 & 0.116 \\
\hline Male & $38(69.1)$ & $35(63.6)$ & & \\
\hline Female & $17(21.9)$ & $20(36.4)$ & & \\
\hline Type of injury, n (\%) & & & 1.000 & $<0.001$ \\
\hline Blunt & $54(98.2)$ & $54(98.2)$ & & \\
\hline Penetrative & $1(1.8)$ & $1(1.8)$ & & \\
\hline Injury severity score & $22[17,26]$ & $18[17,27]$ & 0.455 & 0.033 \\
\hline \multicolumn{5}{|l|}{ Vital signs upon arrival } \\
\hline Systolic blood pressure, $\mathrm{mmHg}$ & $141[112,160]$ & $139[115,160]$ & 0.733 & 0.072 \\
\hline Heart rate, bpm & $78[67,94]$ & $82[67,94]$ & 0.528 & 0.057 \\
\hline Respiratory rate, bpm & $20[16,24]$ & $20[18,22]$ & 0.866 & 0.047 \\
\hline Glasgow coma scale & $14[12,15]$ & $14[12,15]$ & 0.269 & 0.076 \\
\hline Body temperature, ${ }^{\circ} \mathrm{C}$ & $36.4[36.0,36.7]$ & $36.4[35.9,36.6]$ & 0.774 & 0.067 \\
\hline \multicolumn{5}{|l|}{ Comorbidities, n (\%) } \\
\hline Autoimmune disease & $3(5.5)$ & $2(3.6)$ & 1.000 & 0.087 \\
\hline Chronic heart failure & $2(3.6)$ & $3(5.5)$ & 1.000 & 0.087 \\
\hline Chronic kidney disease & $2(3.6)$ & $2(3.6)$ & 1.000 & $<0.001$ \\
\hline Chronic liver disease & $4(7.3)$ & $3(5.5)$ & 1.000 & 0.075 \\
\hline Chronic lung disease & $3(5.5)$ & $2(3.6)$ & 1.000 & 0.087 \\
\hline Dementia & $4(7.3)$ & $2(3.6)$ & 0.679 & 0.161 \\
\hline Diabetes mellitus & $10(18.2)$ & $14(25.5)$ & 0.489 & 0.177 \\
\hline
\end{tabular}

All categorical variables are presented as numbers and percentages (\%), whereas all numerical variables are presented as medians (interquartile range). The balance between the two groups was evaluated using the SMD, with an SMD $>0.1$ as a significant imbalance.

Abbreviations: AHT, anti-hypertensive drug; DNAR, do not attempt resuscitation; SMD, standardised mean difference. 


\begin{tabular}{|c|c|c|c|c|}
\hline Characteristics & $\begin{array}{l}\text { AHT(-) group } \\
(n=55)\end{array}$ & $\begin{array}{l}\text { AHT (+) group } \\
(n=55)\end{array}$ & $P$-value & SMD \\
\hline Malignancy & $2(3.6)$ & $3(5.5)$ & 1.000 & 0.087 \\
\hline Old myocardial infarction & $3(5.5)$ & $2(3.6)$ & 1.000 & 0.087 \\
\hline Psychiatric disease & $1(1.8)$ & $1(1.8)$ & 1.000 & $<0.001$ \\
\hline Stroke & $5(9.1)$ & $6(10.9)$ & 1.000 & 0.061 \\
\hline DNAR order, n (\%) & $1(1.8)$ & $1(1.8)$ & 1.000 & $<0.001$ \\
\hline \multicolumn{5}{|c|}{ Treatment received within $24 \mathrm{~h}$ upon admission, $\mathrm{n}(\%)$} \\
\hline Blood transfusion & $25(45.5)$ & $26(47.3)$ & 1.000 & 0.036 \\
\hline Emergency operation & $16(29.1)$ & $16(29.1)$ & 1.000 & $<0.001$ \\
\hline Interventional radiology & $6(10.9)$ & $6(10.9)$ & 1.000 & $<0.001$ \\
\hline Tracheal intubation & $17(30.9)$ & $19(34.5)$ & 0.839 & 0.078 \\
\hline \multicolumn{5}{|c|}{$\begin{array}{l}\text { All categorical variables are presented as numbers and percentages (\%), whereas all numerical } \\
\text { variables are presented as medians (interquartile range). The balance between the two groups was } \\
\text { evaluated using the SMD, with an SMD }>0.1 \text { as a significant imbalance. }\end{array}$} \\
\hline \multicolumn{5}{|c|}{$\begin{array}{l}\text { Abbreviations: AHT, anti-hypertensive drug; DNAR, do not attempt resuscitation; SMD, standardised } \\
\text { mean difference. }\end{array}$} \\
\hline
\end{tabular}

\section{Table 6}

Relative risk of outcomes analysed using sensitivity analysis

\begin{tabular}{|llll|}
\hline Variables & $\begin{array}{l}\text { AHT(-) group } \\
(\mathbf{n}=\mathbf{5 5})\end{array}$ & $\begin{array}{l}\text { AHT(+) group } \\
(\mathbf{n = 5 5 )}\end{array}$ & $\begin{array}{l}\text { Relative risk } \\
\text { [95\% Cl] }\end{array}$ \\
\hline 28-day mortality, $\mathrm{n}(\%)$ & $6(10.9)$ & $6(10.9)$ & $1.000[0.344-2.910]$ \\
\hline Delirium, $\mathrm{n}(\%)$ & $23(46.9)$ & $9(19.1)$ & $0.391[0.199-0.768]$ \\
\hline All the results were considered statistically significant based on the width of the 95\% Cl. \\
\hline Abbreviations: AHT, anti-hypertensive drug; $\mathrm{Cl}$, confidence interval.
\end{tabular}

\section{Discussion}

To our knowledge, the relationship between the use of anti-hypertensive drugs and mortality or morbidity rates after injury has not yet been investigated. Thus, this is the first study to reveal that the use of anti- 
hypertensive drugs may not affect mortality in older trauma patients, although it may reduce the risk of delirium during hospitalisation.

Delirium is a clinically influential event that commonly occurs in hospitalised geriatric patients. Patients with hypertension or those receiving anti-hypertensive drugs were previously reported to be at risk of developing delirium $[20,21]$. However, our study showed opposite results. Because there has been no previous study on the relationship between the use of anti-hypertensive drugs and delirium, no evidence has been shown to support the direct effect that anti-hypertensive drugs have on reducing the risk of delirium. On the one hand, a systemic inflammatory response is induced after trauma [22]. On the other hand, systemic inflammation and endothelial dysfunction are involved in delirium [23-25]. Thus, it has been hypothesised that the anti-inflammatory effect or protective effect of the endothelial function of anti-hypertensive drugs [13] may have suppressed post-traumatic inflammation and endothelial dysfunction, resulting in a reduced risk of delirium. One basis for this hypothesis is the incidence of VTE, which has also been reported to be at risk due to an acute inflammatory response and endothelial damage after trauma [26]. Although we did not report any statistically significant differences, the risk of VTE tended to be lower in the AHT(+) group.

Previous studies on sepsis showed that the use of anti-hypertensive drugs reduced the risk of in-hospital mortality [14-17]. However, in this study, similar results were not found. One possible reason for this is the small number of outcomes. Our study population had an in-hospital mortality rate of approximately $5 \%$; however, previous studies had 30 - to 90 -day mortality rates of approximately $20 \%-40 \%$.

In retrospect, a study of cases involving a cluster of severe traumas may be helpful. The difference in mortality among patients with an ISS $\geq 16$ was also examined, although the results appeared to have insufficient detection ability, because of the small study population. Alternatively, the degree of systemic inflammation may be small, and the anti-inflammatory effect of anti-hypertensive drugs may not have affected the mortality of trauma patients.

Consequent complications, such as delirium [27, 28], worsen the prognosis of geriatric patients with trauma [8]. Therefore, the prevention of delirium is important. Although the use of anti-hypertensive drugs before the injury may have a preventive effect on delirium, one of the limitations of this study is whether the re-administration or the induction of anti-hypertensive drugs after hospitalisation has a preventive effect on delirium. In cases of polytrauma, older patients may be likely to experience haemorrhagic shock during the acute phase, or may be suddenly exacerbated due to infection or re-bleeding, even after overcoming the hyperacute phase. Thus, there is no clear recommendation regarding when to resume the oral administration of anti-hypertensive drugs. Further studies should investigate the appropriate time to resume the use of anti-hypertensive drugs and the mechanism underlying their preventive effect on delirium.

This study has some limitations. First, this was a retrospective cohort study conducted in a single centre. Thus, we could not eliminate the bias in the backgrounds of our study population. Second, we used propensity score matching, which could not access the effect of unknown variables that might have led 
to biased results. Third, due to the retrospective design, there was no data on patient compliance until the day before the injury. If patients have a history of oral anti-hypertensive drug administration without actually taking oral anti-hypertensive drugs, then the interpretation of the results may be different.

\section{Conclusions}

Regular use of anti-hypertensive drugs did not affect the outcome of geriatric trauma patients. In addition, many in-hospital complications were not affected by anti-hypertensive drugs; however, the incidence of delirium was reduced in patients who regularly received anti-hypertensive drugs.

\section{List Of Abbreviations}

AHT $(+) \quad$ Patients who had received anti-hypertensive drugs before admission

AHT(-) Patients whohad not received anti-hypertensive drugs before admission

$\mathrm{Cl} \quad$ Confidence interval

ISS Injury severity score

RR Relative risk

SMD Standardised mean difference

VTE Venous thromboembolism

\section{Declarations}

Ethics approval and consent to participate: All procedures performed in studies involving human participants were in accordance with the ethical standards of the institutional and/or national research committee and with the 1964 Declaration of Helsinki and its later amendments or comparable ethical standards. The protocol for this single-centre, retrospective cohort study was approved by the Medical Ethics Committee of Juntendo University Shizuoka Hospital (approval number: E21-0089). The study was conducted in accordance with the Strengthening the Reporting of Observational Studies in Epidemiology guidelines [18].

Consent for publication: Not applicable. 
Availability of data and materials:The datasets used and/or analysed during the current study are available from the corresponding author on reasonable request.

Competing interests: The authors declare that they have no competing interests.

Funding: This research did not receive any specific grant from funding agencies in the public, commercial, or not-for-profit sectors.

Authors' contributions: $\mathrm{HN}$ and $\mathrm{YY}$ designed the study. $\mathrm{KI}$ and HO supervised the data collection. SO, KIM, $\mathrm{YK}$, and $\mathrm{KJ}$ corrected the data. HN conducted the literature search and statistical analysis, interpreted the data, and drafted the manuscript. All authors read and approved the final manuscript. HN takes responsibility for the paper as a whole.

Acknowledgements: This work was supported in part by a Grant-in-Aid for Special Research in Subsidies for ordinary expenses of private schools from The Promotion and Mutual Aid Corporation for Private Schools of Japan. We want to thank Editage (www.editage.com) for English language editing.

\section{References}

1. Hashmi A, Ibrahim-Zada I, Rhee P, Aziz H, Fain MJ, Friese RS, et al. Predictors of mortality in geriatric trauma patients: a systematic review and meta-analysis. J Trauma Acute Care Surg. 2014;76:894901.

2. Müller FS, Meyer OW, Chocano-Bedoya P, Schietzel S, Gagesch M, Freystaetter G, et al. Impaired nutritional status in geriatric trauma patients. Eur J Clin Nutr. 2017;71:602-6.

3. Joseph B, Pandit V, Zangbar B, Kulvatunyou N, Hashmi A, Green DJ, et al. Superiority of frailty over age in predicting outcomes among geriatric trauma patients: a prospective analysis. JAMA Surg. 2014;149:766-72.

4. Campbell-Furtick M, Moore BJ, Overton TL, Laureano Phillips JL, Simon KJ, Gandhi RR, et al. Posttrauma mortality increase at age 60: a cutoff for defining elderly? Am J Surg. 2016;212:781-5.

5. Bradburn E, Rogers FB, Krasne M, Rogers A, Horst MA, Beelen MJ, et al. High-risk geriatric protocol: improving mortality in the elderly. J Trauma Acute Care Surg. 2012;73:435-40.

6. Azu MC, McCormack JE, Huang EC, Lee TK, Shapiro MJ. Venous thromboembolic events in hospitalized trauma patients. Am Surg. 2007;73:1228-31.

7. Prabhakaran K, Gogna S, Lombardo G, Latifi R. Venous thromboembolism in geriatric trauma patients-risk factors and associated outcomes. J Surg Res. 2020;254:327-33.

8. Adams SD, Holcomb JB. Geriatric trauma. Curr Opin Crit Care. 2015;21:520-6. 
9. Bromfield SG, Ngameni CA, Colantonio LD, Bowling CB, Shimbo D, Reynolds K, et al. Blood pressure, antihypertensive polypharmacy, frailty, and risk for serious fall injuries among older treated adults with hypertension. Hypertension. 2017;70:259-66.

10. Klein D, Nagel G, Kleiner A, Ulmer H, Rehberger B, Concin $H$, et al. Blood pressure and falls in community-dwelling people aged 60 years and older in the VHM\&PP cohort. BMC Geriatr. 2013;13:50.

11. Tinetti ME, Han L, Lee DS, McAvay GJ, Peduzzi P, Gross CP, et al. Antihypertensive medications and serious fall injuries in a nationally representative sample of older adults. JAMA Intern Med. 2014;174:588-95.

12. Woolcott JC, Richardson KJ, Wiens MO, Patel B, Marin J, Khan KM, et al. Meta-analysis of the impact of 9 medication classes on falls in elderly persons. Arch Intern Med. 2009;169:1952-60.

13. Silva IVG, de Figueiredo RC, Rios DRA. Effect of different classes of antihypertensive drugs on endothelial function and inflammation. Int J Mol Sci. 2019;20:3458.

14. Mortensen EM, Restrepo MI, Copeland LA, Pugh JA, Anzueto A, Cornell JE, et al. Impact of previous statin and angiotensin II receptor blocker use on mortality in patients hospitalized with sepsis. Pharmacotherapy. 2007;27:1619-26.

15. Kim J, Kim YA, Hwangbo B, Kim MJ, Cho H, Hwangbo Y, et al. Effect of antihypertensive medications on sepsis-related outcomes: a population-based cohort study. Crit Care Med. 2019;47:e386-93.

16. Wiewel MA, van Vught LA, Scicluna BP, Hoogendijk AJ, Frencken JF, Zwinderman AH, et al. Prior use of calcium channel blockers is associated with decreased mortality in critically ill patients with sepsis: a prospective observational study. Crit Care Med. 2017;45:454-63.

17. Lee CC, Lee MG, Lee WC, Lai CC, Chao CC, Hsu WH, et al. Preadmission use of calcium channel blocking agents is associated with improved outcomes in patients with sepsis: a population-based propensity score-matched cohort study. Crit Care Med. 2017;45:1500-8.

18. von Elm E, Altman DG, Egger M, Pocock SJ, Gøtzsche PC, Vandenbroucke JP, et al. The Strengthening the Reporting of Observational Studies in Epidemiology (STROBE) statement: guidelines for reporting observational studies. Lancet. 2007;370:1453-7.

19. Kanda Y. Investigation of the freely available easy-to-use software "EZR" for medical statistics. Bone Marrow Transplant. 2013;48:452-8.

20. Harrison PJ, Luciano S, Colbourne L. Rates of delirium associated with calcium channel blockers compared to diuretics, renin-angiotensin system agents and beta-blockers: an electronic health records network study. J Psychopharmacol. 2020;34:848-55.

21. Zaal IJ, Devlin JW, Peelen LM, Slooter AJ. A systematic review of risk factors for delirium in the ICU. Crit Care Med. 2015;43:40-7.

22. Schlömmer C, Meier J. Inflammatory response in trauma patients: are there ways to decrease the inflammatory reaction? Curr Opin Anaesthesiol. 2020;33:253-8.

23. Kealy J, Murray C, Griffin EW, Lopez-Rodriguez AB, Healy D, Tortorelli LS, et al. Acute inflammation alters brain energy metabolism in mice and humans: role in suppressed spontaneous activity, 
impaired cognition, and delirium. J Neurosci. 2020;40:5681-96.

24. Hughes CG, Patel MB, Pandharipande PP. Pathophysiology of acute brain dysfunction: what's the cause of all this confusion? Curr Opin Crit Care. 2012;18:518-26.

25. Hughes CG, Morandi A, Girard TD, Riedel B, Thompson JL, Shintani AK, et al. Association between endothelial dysfunction and acute brain dysfunction during critical illness. Anesthesiology. 2013;118:631-9.

26. Bahloul M, Dlela M, Bouchaala K, Kallel H, Ben Hamida CB, Chelly H, et al. Post-traumatic pulmonary embolism: incidence, physiopathology, risk factors of early occurrence, and impact outcome. A narrative review. Am J Cardiovasc Dis. 2020;10:432-43.

27. Inouye SK, Westendorp RG, Saczynski JS. Delirium in elderly people. Lancet. 2014;383:911-22.

28. Ní Chróinín D, Francis N, Wong P, Kim YD, Nham S, D’Amours S. Older trauma patients are at high risk of delirium, especially those with underlying dementia or baseline frailty. Trauma Surg Acute Care Open. 2021;6:e000639.

\section{Figures}






Figure 1

Flow chart of participant inclusion. 